\title{
LEAN ARCHIVES: O emprego do Lean Office na gestão de arquivos
}

Marcelo Cavaglieri

Mestre em Gestão de Unidades de Informação pela UDESC. Especialista em Gestão Empresarial pela FMP

Jordan Paulesky Juliani

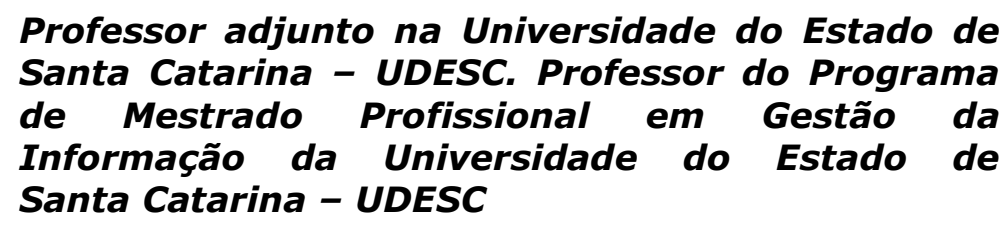

http://dx.doi.org/10.1590/1981-5344/2726

Neste estudo, buscou-se aplicar o Lean office na gestão de arquivos tendo como objetivo verificar a aplicabilidade do pensamento Lean na arquivística. Quanto ao método utilizado, caracteriza-se por ser uma pesquisa-ação, de abordagem quali-quantitativa, classificada como exploratória e descritiva. A coleta dos dados realizou-se por meio de observação participante, entrevista não estruturada e realização de um grupo focal. Em relação à aplicação da pesquisa, seguiram-se os seguintes passos: Treinamento e conscientização dos colaboradores para o pensamento Lean; MFV - estado atual; MFV - estado Futuro; Plano de ação e Avaliação e discussão dos resultados. Entre os resultados obtidos da pesquisa realizada, destaca-se, de forma quantitativa, a redução de desperdícios com ganhos significativos do Lead Time, diminuindo o tempo gasto para processar as atividades e tempo em que o material fica parado, esperando para ser processado. Ganhos financeiros também foram obtidos, com mais aproveitamento dos recursos e uma reformulação na forma de guardar os documentos. De forma qualitativa, destaca-se um melhor ambiente de trabalho com práticas da gestão visual para comunicação das informações e aumento da eficiência do serviço prestado, gerando mais satisfação do cliente.

Palavras-chave: Lean archives; Lean office; Arquivo empresarial; Gestão documental; Gestão da informação. 


\section{LEAN ARCHIVES: The use of Lean Office in archive management}

This study, it was sought to apply the Lean office in the document file management having as purpose to verify the applicability of Lean Thinking in archivology. Regarding to the method used, it is characterized as a research-action in a quali-quantitative approach, classified as exploratory and descriptive. The data collection was held through a participative observation, a non-structured interview, and a focus group realization. Regarding to the research application, the following steps were performed: Training and worker awareness about the Lean thinking; VFM - current state; VFM - future state; Action plan and results evaluation and discussion. Among the obtained research results, it stands out in a quantitative way the reduction of waste, with significant gains of Lead Time, diminishing the time to process the activities and the time at which the material awaits to be processed. Financial gains were also obtained with a better use of resources and a redesigning of the way to keeping the documents. In a qualitative way, a better working environment is highlighted with visual management practices to information communication and increase of the service efficiency in bringing more customer satisfaction.

Keywords: Lean Archives; Lean Office; Company archives; Document management; Information management.

Recebido em 25.04.2016 Aceito em 26.07.2016

\section{Introdução}

Prevaleceu-se, por muito tempo, o entendimento de que os arquivos empresariais eram apenas um setor de depósito de documentos, utilizado eventualmente para comprovar alguma transação em caso de fiscalização. Com a atribuição da devida importância à informação no processo decisório das organizações, o papel do arquivo nas empresas foi substancialmente modificado, passando de um simples depósito de documentos a um setor estratégico, capaz de organizar, armazenar e processar informações utilizadas pelos diversos setores da empresa a realização de suas atividades. Nesse cenário, o arquivo passa a ser 
entendido como uma fonte de informações valiosas e confiáveis para nortear decisões de planejamento e ações gerenciais.

Para ter valor, a informação precisa estar organizada e acessível, de modo que possa ser útil aos colaboradores da empresa. Reforça-se, portanto, a necessidade de uma gestão da informação eficiente, que possibilite com que as informações certas cheguem às pessoas certas no momento e no formato em que elas desejarem, com o menor consumo de recursos organizacionais possível, eliminando gargalos e desperdícios. A empresa eficiente é àquela que utiliza racionalmente os recursos para entregar valor aos clientes. As técnicas e ferramentas que sustentam a gestão eficiente precisam ser empregadas em toda a estrutura organizacional, inclusive nos arquivos empresariais.

A escassez de recursos e o fenômeno da concorrência fez com que a Empresa Japonesa Toyota desenvolvesse um sistema de gestão focado na eficiência e eliminação de desperdícios. Este sistema foi batizado de Sistema Toyota de Produção (STP), cujo sucesso obtido permitiu transformar a montadora Toyota em uma das maiores do mundo. Deste sistema de gestão derivou-se o pensamento Enxuto ou Lean Thinking. Esta filosofia de gestão parte da redução e eliminação desperdícios nos processos da indústria até o desenvolvimento uma cultura organizacional voltada para a melhoria continua.

O Lean Office, também conhecido como escritório enxuto, surgiu da aplicação dos princípios enxutos, oriundos das empresas industriais em que se desenvolveu o Lean Thinking, para o ambiente administrativo. Sua aplicação permite tornar o fluxo de trabalho e as informações mais visíveis, possibilitando uma gestão da informação e uma gestão de materiais mais apropriados com a identificação do fluxo de valor e a eliminação de desperdícios (WOMACK; JONES, 2003).

Esta pesquisa se propôs a verificar aplicabilidade do conceito de Lean Office na gestão de arquivos, como alternativa de solução para problemas relacionados à demora na recuperação de documentos, ao baixo retorno de empréstimos de documentos, e a falta de organização física e de padronização na criação de documentos. A pesquisa foi desenvolvida no grupo empresarial Santa Fé. Atualmente, o Grupo perfaz onze empresas ativas nas áreas de comercialização de veículos, administração de consórcios, construção civil, hotelaria e administração de shopping center.

A formulação do problema deste estudo está na aplicação dos conceitos do Lean Office em um ambiente distante da aplicação usual. Neste sentido, pretende-se responder à seguinte questão de pesquisa: Como aplicar o Lean Office na gestão de arquivos? A questão de pesquisa retrata uma problemática voltada às melhorias necessárias à gestão de arquivos, pois com a massa documental cada vez maior, a gestão se torna desafiadora e, novas técnicas devem ser implantadas para garantir o sucesso e o bom funcionamento desses ambientes.

O objetivo geral da pesquisa é aplicar o Lean office na gestão de arquivos. Já os objetivos específicos são: 
a) identificar os processos do arquivo que tem relação com seus clientes;

b) selecionar dentre os processos identificados aqueles que apresentam mais criticidade para o andamento do negócio;

c) identificar desperdícios por meio do Mapeamento de Fluxo de Valor (MFV);

d) avaliar oportunidades de melhorias nos processos mapeados;

d) apresentar oportunidades de melhoria por meio do MFV do estado futuro;

f) identificar e aplicar as técnicas e ferramentas do Lean Office para promover as melhorias nos processos mapeados;

g) avaliar os resultados da aplicação do Lean Office na gestão do arquivo do Grupo Santa Fé.

A pesquisa iniciou-se com o levantamento bibliográfico sobre arquivos empresariais, pensamento enxuto (Lean) e Lean Office, conforme apresentado nos tópicos a seguir.

\section{Arquivos empresariais}

Um dos aspectos centrais da gestão arquivística contemporânea está relacionada ao volume de documentos gerados e consumidos pelas organizações. Este fenômeno é impulsionado pelas plataformas tecnológicas que tornam o processo de criação e distribuição de documentos bastante facilitado. No entanto, com a facilidade de criar novos documentos surge a preocupação com os conteúdos criados, manipulados e disseminados, bem como as competências profissionais e organizacionais em lidar com esse volume de informação (MARCHIORI, 2002).

Com essa dificuldade no tratamento da informação, aumenta a responsabilidade dos profissionais que trabalham nesses ambientes, pois ao mesmo tempo que precisam classificar toda a massa documental produzida pela empresa, também são responsáveis por tornar esse espaço mais interativo, transformando o arquivo em uma unidade de informação capaz de estabelecer uma relação efetiva de troca de informação e conhecimento com os stakeholders.

Os arquivos empresariais, por sua vez, são locais destinados à guarda de todo volume documental produzido pelas empresas ao longo da vida útil. Esses locais necessitam de estrutura e tecnologia adequadas para tratar e conservar os documentos durante o período de vigência, seja no suporte físico ou digital, pois eles fazem parte do patrimônio da empresa e devem contribuir na gestão.

No Brasil, a Lei 8.159, de 8 de janeiro de 1991, dispõe sobre a Política Nacional de Arquivos Públicos e Privados e dá outras providências. 
Em seu art. 20, define arquivo como: [...] os conjuntos de documentos produzidos e recebidos por órgãos públicos, instituições de caráter público e entidades privadas, em decorrência do exercício de atividades específicas, bem como por pessoa física, qualquer seja o suporte da informação ou a natureza dos documentos (BRASIL. Presidência da República, 1991, p. 1).

A mesma Lei, em seu art. 110, especifica arquivos privados como sendo "[...] conjuntos de documentos produzidos ou recebidos por pessoas físicas ou jurídicas, em decorrência de suas atividades" BRASIL. Presidência da República, 1991, p. 1).

A interação entre as pessoas e os arquivos também dependem de uma efetiva gestão de documentos que se constitui num caminho seguro, ágil e eficiente para as empresas se destacarem de seus concorrentes, prevenindo principalmente que a massa documental não se perca ao longo da tramitação, possibilitando que o arquivo funcione como uma unidade de informação; ponto a ser discutido no próximo tópico (CAVAGLIERI; LOPES; ROSÁRIO, 2009).

\subsection{Arquivo empresarial como unidade de informação}

Dentro das empresas, é fundamental que os documentos estejam dispostos e ordenados de forma a servir os gestores de modo ágil e eficiente, sendo que a metodologia de organização deve-se preocupar com estágios de desenvolvimento da massa documental e, sempre, com a finalidade de atender as necessidades da organização a que serve.

Apesar de as técnicas arquivísticas facilitarem a organização da massa documental, a organização do acervo deve ser pensada e estruturada de acordo com a realidade de cada empresa, pois sua demanda e utilização é que guiarão o profissional na organização. Nesse sentido, Pinto (2001, p. 5) acredita em uma visão mais atuante da arquivística na gestão das empresas, propondo uma nova metodologia de abordagem, que procure "[...] cada vez menos estabelecer e impor regras operativas e cada vez mais conhecer e compreender o fenômeno e o processo informacional, para depois apresentar as soluções mais adequadas."

Com essa visão mais moderna das funções arquivísticas, é possível pensar no arquivo como unidade de informação e não mais como depósito de documentos, destacado por Dudziak (2010). O autor relata que para as empresas, em que até pouco tempo o arquivo era compreendido como um simples depósito de papéis velhos, constituindo-se muitas vezes de pilhas ou caixas de documentos desordenados em que o profissional arquivista recolhia e conservava esses velhos papéis, preservando-os da destruição que, geralmente, os esperava.

Devido a constante profissionalização de pessoal e a maior preocupação em contratar profissionais capacitados para cuidar da massa documental, os arquivos têm-se tornado grandes fontes de pesquisa, 
assumindo papel cada vez mais importante e com mais destaque nas organizações.

Cavalcante e Valentim (2010, p. 235) descrevem que "a informação e o conhecimento, direta ou indiretamente, estão presentes em todos os processos e atividades organizacionais." Assim, entende-se que ao absorver e usufruir da melhor forma possível os recursos de informação, as organizações tendem a obter um melhor desenvolvimento e competitividade ante o mercado. Nesse sentido, quanto mais informações relevantes os administradores e gestores das empresas tiverem sobre determinado assunto, melhor e com mais convicção poderão decidir sobre ele. Cabe ao profissional da informação que trabalha nessas organizações selecionar informações úteis para auxiliá-los e ter uma atuação mais dinâmica. Para tanto, deve-se usar técnicas de gestão e tecnologias que facilitem esse processo, sempre com a finalidade de recuperar a informação com segurança e agilidade.

O uso das Tecnologias de Informação e Comunicação (TIC) colabora com o desafio das empresas em transformar a informação contida em seu ambiente em diferencial competitivo para agregar maior valor a produtos e serviços. Neste sentido, as TICs têm-se tornado grandes aliadas nos processos que envolvem à gestão documental. Seu uso contribui não apenas na disseminação da informação, mas também na guarda e conservação de muitos documentos que têm valor histórico significativo e precisam de um cuidado especial para não se deteriorarem. Com a digitalização desses documentos é possível tornar as informações pública acessíveis a todos.

Assim, para garantir o bom funcionamento dos arquivos e possibilitar que a informação esteja acessível, profissionais estão em constante busca de novos conhecimentos, tecnologias e técnicas que auxiliem uma gestão documental mais ágil e eficaz. No próximo capítulo é exposto uma nova filosofia de gestão que pode contribuir para a melhora desses ambientes.

\section{Pensamento Lean}

Para entender a filosofia Lean, inicialmente é preciso entender como ela surgiu, assim destaca-se que o desenvolvimento da Produção Enxuta teve como base o Sistema Toyota de Produção (STP). Sua história está intrinsecamente ligada ao crescimento do sistema de produção de automóveis, vivenciado no início da década de 1940 pela montadora Toyota e também a mudança de modelos na forma de gerenciar os processos, possibilitando maior produtividade e redução de custos em consequência.

Com o final da Segunda Guerra Mundial, o Japão enfrentava um cenário de escassez de recursos de produção e de capital para a produção em massa. Para se manter no mercado, o presidente da Toyota, na época, o engenheiro Eiji Toyoda foi estudar o parque de produção Rouge da Ford nos Estados Unidos, considerado o mais eficiente do mundo na produção 
de automóveis da época. No final de sua avaliação, retornou ao seu país junto ao engenheiro de produção Taiichi Ohno, concluindo que a produção em massa não oferecia no Japão os mesmos resultados que nos Estados Unidos em termos de desenvolvimento econômico. Em vista disso, era preciso pensar um novo sistema de produção mais eficiente para a realidade do país (GREEF; FREITAS; ROMANEL, 2012).

Discussões e observações dos gerentes e engenheiros da Toyota Motor Company, sobre como melhorar sua produtividade e aumentar o retorno financeiro, apontaram para a existência de desperdícios nas linhas de produção dos veículos. Taiich Ohno, um dos responsáveis pela criação do STP, descrevia que o passo preliminar para a aplicação de um novo sistema de produção era identificar completamente os desperdícios descritos a seguir:

a) desperdício de superprodução: deve-se evitar a produção em excesso ou cedo demais;

b) desperdício de tempo disponível (espera): o tempo de trabalho dos funcionários deve ser completamente preenchido;

c) desperdício em transporte: evitar movimento excessivo de pessoas, peças e informações;

d) desperdício do processamento em si: utilizar máquinas e sistemas adequados para que a produção possa fluir com maior rapidez;

e) desperdício de estoque disponível: o tamanho do estoque deve ser adequado à necessidade de armazenamento;

f) desperdício de movimento: o ambiente de trabalho deve estar organizado, evitando movimentos longos de profissionais para desenvolver suas tarefas;

g) desperdício de produzir produtos defeituosos: a qualidade deve estar sempre em primeiro lugar, para evitar a confecção em duplicidade de peças que podem apresentar problemas (OHNO, 2006).

Com o auxílio dos próprios funcionários, novos modelos de produção para facilitar as atividades rotineiras e eliminação de desperdício foram implantados. Assim, a Toyota desenvolveu uma série de técnicas de aperfeiçoamento da produção, consolidando o STP e o Modelo Toyota, que originaram o conceito de Produção Enxuta (GREEF; FREITAS; ROMANEL, 2012).

A aplicação dos princípios Lean é irrestrita ao modelo de negócio e ao porte da empresa, pois trabalha com técnicas que ajudam a mobilizar as pessoas na busca constante de melhores resultados, conforme pode ser observado na seção seguinte. 


\subsection{Lean Office como filosofia de gestão}

O Lean Office se desenvolveu da apropriação dos conceitos do Lean Thinking, inicialmente praticados apenas no chão de fábricas, para o ambiente administrativo dos escritórios. Sua aplicação com êxito na produção industrial possibilitou que os escritórios fizessem uma adaptação do uso das ferramentas em seu ambiente, tornando a gestão da informação e de materiais mais ágil, com a eliminação de procedimentos ociosos que geravam desperdícios e, assim, criavam mais valor ao fluxo de informação e aos processos administrativos.

Para Tapping e Shuker (2010), a aplicação dos conceitos Lean em áreas administrativas recebe o nome de Lean Office e é de grande importância, visto que $60 \%$ a $80 \%$ dos custos envolvidos para atender a demanda de um cliente é de natureza administrativa. Foi com a finalidade de reduzir esses percentuais altos de custos administrativos que o Lean Office nasceu e vem ganhando cada vez mais espaço, quebrando paradigmas de técnicas antigas no âmbito global, pois com mais agilidade nos trâmites administrativos, as empresas conseguem reduzir os custos e atender o cliente de forma mais ágil.

Greef, Freitas e Romanel (2012) destacam que o Lean Office foi o conceito criado para integrar as ferramentas e técnicas de gestão já existentes, àquelas incorporadas do Lean Thinking. Tal aplicação possibilitou atribuir importâncias às atividades de informação, controle de estoque e movimentações inseridas em escritórios; tornou a prestação dos serviços previstos mais efetiva, atendendo às necessidades dos clientes, consequentemente, proporcionando-Ihes satisfação.

O Lean Office, se aplicado corretamente, possibilita a redução do desperdício da superprodução de documentos impressos, a redução do tempo de prestação de serviços, a restrição do movimento excessivo de pessoas entre repartições, a melhoria do uso de recursos humanos subutilizados, a redução dos níveis hierárquicos e a minimização dos custos de armazenamento de documentos (SCALERA, 2012). Na próxima seção são expostas algumas Técnicas e ferramentas que auxiliam as empresas a se tornarem Lean.

\subsection{Técnicas e ferramentas do Lean}

O conceito do pensamento enxuto, visto na seção anterior, extrapola - campo da teoria e expõem ferramentas práticas que auxiliam as empresas e os gestores a transformá-las em enxutas. Entre as principais ferramentas Lean destacam-se: 5S; Trabalho Padronizado; Células de Trabalho; Gestão Visual; Mapeamento do Fluxo de Valor; Método FIFO (First in - First out); Just In Time; Fluxo contínuo; Fluxo puxado; Kanban; Takt Time; Jidoka; Heijunka; Kaizen; Os Cinco Porquês, A3 e Qualidade da Fonte.

Esta seção resume no quadro 1 as técnicas e ferramentas utilizadas nesta pesquisa. 
Quadro 1 - Técnicas e ferramentas do Lean Office utilizadas nesta pesquisa

\begin{tabular}{|c|c|}
\hline $\begin{array}{l}\text { Técnica / } \\
\text { Ferramenta }\end{array}$ & Descrição \\
\hline $\begin{array}{l}\text { Mapeamento do } \\
\text { Fluxo de Valor }\end{array}$ & $\begin{array}{l}\text { O Mapeamento de Fluxo de Valor (MFV), também conhecido como Value } \\
\text { Streaming Mapping (VSM), é uma ferramenta que possibilita revelar } \\
\text { oportunidades de melhoria. Mediante o mapeamento da situação atual, } \\
\text { juntamente à descrição do mapeamento da situação ideal ou estado } \\
\text { futuro, com a aplicação dos conceitos Lean é possível visualizar melhor } \\
\text { as interlocuções indesejadas no caminho e eliminá-las para que o } \\
\text { produto ou serviço seja entregue com mais qualidade e valor agregado } \\
\text { ao cliente final. }\end{array}$ \\
\hline Kaizen & $\begin{array}{l}\text { O Kaizen tem significado de melhoria contínua e deve ser aplicado } \\
\text { enquanto elemento cultural, que facilita a obtenção de resultados e } \\
\text { objetivos das empresas previstos pelos gestores e também a certeza de } \\
\text { haver a participação de todos os colaboradores do ambiente, } \\
\text { independentemente do nível hierárquico (GREEF; FREITAS; ROMANEL, } \\
\text { 2012). }\end{array}$ \\
\hline $\begin{array}{l}\text { Trabalho } \\
\text { Padronizado }\end{array}$ & $\begin{array}{l}\text { O trabalho padronizado parte da criação de procedimentos com } \\
\text { especificações precisas que visem ao melhor resultado de trabalho, } \\
\text { sequenciando-o de maneira mais eficaz, permitindo que outras pessoas } \\
\text { executem a mesma atividade sem depender de quem as criou. }\end{array}$ \\
\hline
\end{tabular}

Fonte: Os autores.

\section{Materiais e métodos}

A presente pesquisa se caracteriza como aplicada em relação à sua natureza, uma vez que objetiva gerar conhecimentos dirigidos à solução de um ou mais problemas específicos da organização, ou seja, que os resultados sejam aplicados imediatamente na solução de problemas à medida que forem sendo identificados.

Em relação ao método, o estudo se caracteriza como uma pesquisaação, em que há uma participação direta dos envolvidos na pesquisa com a solução do problema. Assim, aplicar-se-ão os princípios do Lean Office nas empresas do Grupo Santa Fé, com objetivo de realizar um estudo do ambiente e dos processos e da interpretação do fluxo de valor dos clientes do arquivo, com ênfase em avaliar oportunidades de melhorias para eliminação dos desperdícios com a aplicação das técnicas e ferramentas Lean. Thiollent (1997) esclarece que o foco da pesquisa-ação é diagnosticar problemas e buscar soluções à organização, com caráter interrogativo-crítico, o pesquisador deve conduzir os atores a formular perguntas acerca da situação em que vivem no ambiente de trabalho, promovendo ampla interação entre pesquisadores e membros representativos da situação investigada.

No que se refere à natureza das variáveis pesquisadas, caracterizase por ser uma pesquisa quali-quantitativa, visto que o problema sugere a utilização das duas abordagens, tendo em vista que é necessário conhecer os processos que envolvem a gestão de arquivos e as possíveis aplicações das ferramentas do Lean Office. Também mensura estatisticamente as 
melhorias obtidas, por meio das medidas de desempenho que irão avaliar o lead time e os ganhos financeiros e o espaço físico.

Devido à necessidade de conhecer alguns aspectos relacionados à gestão documental e da informação do Grupo Santa Fé, o estudo se classifica como exploratório e descritivo. Exploratório, pois não há muito conhecimento acumulado e sistematizado e contribuirá na exploração do tema e na exposição de bibliografias a respeito do assunto, buscando diversos tipos de informações relevantes para cumprir os objetivos, entender melhor o problema e solucioná-lo e descritivo porque se propõe a descrever as características dos processos e da gestão do Grupo estudado.

\subsection{Universo da pesquisa}

Com o objetivo de aplicar o Lean Office na gestão de arquivos, optou-se por desenvolver a pesquisa no arquivo do Grupo Santa Fé. O Grupo conta atualmente com onze empresas ativas, gerando cerca 2.500 empregos diretos e indiretos, com atuação em setores como: comercialização de veículos, administração de consórcios, construção civil, hotelaria e administração de shopping center.

\subsection{Técnica de coleta de dados}

A coleta dos dados foi feita por meio de observação participante, entrevista não estruturada e da técnica do grupo focal. A junção das técnicas possibilitou mais aproximação com os agentes envolvidos na pesquisa, além de se aprofundar na discussão dos problemas críticos de cada setor da empresa. Morgan (1997) descreve que o grupo focal é uma técnica de pesquisa qualitativa, proveniente das entrevistas grupais.

A junção dessas três técnicas de coleta de dados: observação participante, entrevista não estruturada e grupo focal, confere a confiabilidade dos dados colhidos e, assim, a certeza na decisão de implantar as melhorias necessárias para solucionar os problemas observados.

\subsection{Procedimentos de coleta de dados}

A observação participante realizou-se diariamente em campo, tendo em vista que o proponente da pesquisa trabalha no local de estudo e tem acesso a todos os setores. Essa observação crítica dos setores da empresa foi preponderante para identificar os pontos mais críticos que tinham relação com o arquivo, e assim a escolha do setor a ser estudado.

A entrevista não estruturada aconteceu com alguns funcionários dos setores da empresa, antes e após a aplicação do grupo focal. Antes, com a finalidade de identificar pontos críticos e analisar a viabilidade de elimina-los, e após, com o intuito de discutir algumas medidas que não ficaram claras, permitindo avaliar as mudanças efetuadas. 
Após as duas análises descritas acima, escolheram-se dois processos do despachante para serem analisados, ambos relacionados as empresas do grupo que comercializam automóveis. A escolha dos dois processos se deu pelo fato de envolver todas as atividades de criação, guarda e recuperação dos documentos. Os clientes dos dois processos são os colaboradores internos do Grupo Santa Fé, que são os responsáveis pela criação dos documentos e por solicitar a recuperação dos mesmos após seu arquivamento. Os processos escolhidos foram:

Processo A: recebimento de documentos, com o objetivo de identificar todas as atividades que envolvam, desde a criação dos documentos relacionados à compra e venda de um automóvel, até o envio para o arquivo.

Processo B: recuperação da informação, com o intuito de mapear atividades que envolvem a solicitação, a busca e a recuperação de determinado documento.

Uma vez delimitado os processos, pôde-se estabelecer o objetivo do grupo focal e preparar a organização. O objetivo principal foi fazer um treinamento e conscientização dos colaboradores para o pensamento Lean, mapear as atividades dos dois processos estudados, identificar possíveis melhorias e juntos traçar um plano de ação para executar as ações propostas.

Como forma de ilustrar o emprego da filosofia do Lean Office na gestão arquivística será detalhado neste artigo somente o Processo $A$.

\subsection{Procedimentos de análise dos dados}

Durante o procedimento de análise dos dados, identificou-se a necessidade de estabelecer métricas que permitissem ter uma melhor avaliação das melhorias propostas no plano ação. A criação de métricas para avaliar os resultados foi necessária para se chegar à conclusão de que a implantação da filosofia Lean nos arquivos pode ou não trazer resultados significativos à organização estudada, ou a este ramo de atividade. Para mensurar os ganhos relacionados aos resultados, a aplicação da pesquisa teve como fundamento a análise do parâmetro lead time (tempo de espera), com a finalidade de comparar o tempo do processo do estado atual com o futuro, além de poder mensurar os tempos de recuperação da informação antes e depois da aplicação do método proposto. A fórmula do lead time é calculada da seguinte forma:

\section{Lead time: tempo de processamento + tempo de retenção}

Tempo de processamento: tempo gasto para processar as atividades.

Tempo de retenção: tempo em que o material fica parado, esperando para ser processado. 
Outra medida considerada é a financeira, com objetivo de medir os custos atuais e os futuros para desempenhar o processo. Adotou-se essa medida para segmentar ainda mais a política atual da empresa que é de redução de custos sem perder a eficiência.

A última medida utilizada foi a de espaço físico, tendo em vista que o arquivo atual já não suporta mais o crescimento documental e o aluguel de novo espaço iria gerar um custo adicional que não está no plano orçamentário do Grupo.

\section{Aplicação do lean office na gestão de arquivos}

Neste capítulo, apresentam-se a descrição e a análise dos dados obtidos por meio da aplicação dos conceitos do Lean Office na gestão de arquivos. Os procedimentos de aplicação tiveram embasamento nos objetivos propostos neste estudo, além dos conhecimentos adquiridos com a aplicação do Lean Office em outros segmentos. Entretanto, seguindo o contexto da pesquisa, adotaram-se os passos descritos no fluxograma apresentado na Figura 1 para implantar o Lean Office no arquivo do Grupo Santa Fé.

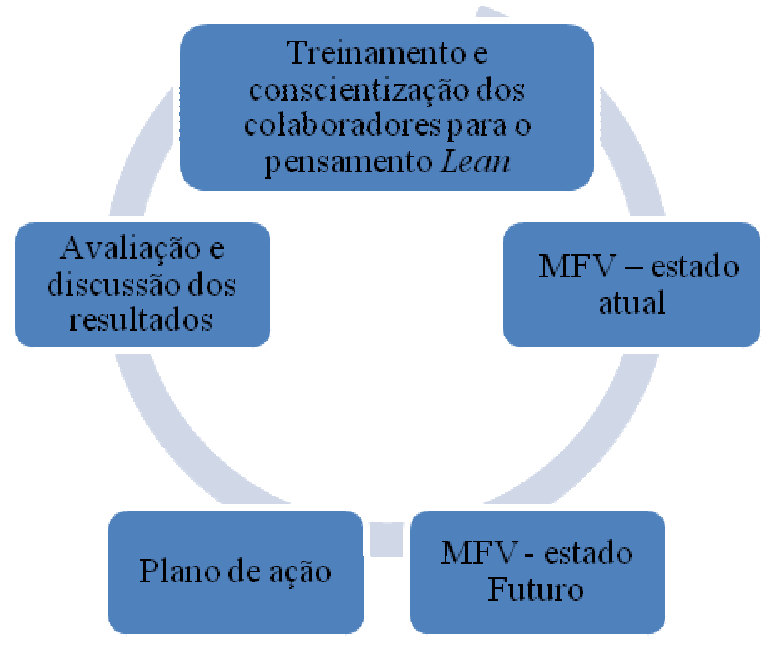

Figura 1 - Passos para implantação do Lean Office

Fonte: Os autores.

A metodologia adotada para implantação da filosofia Lean está representada em um fluxograma de ciclo, pois para que a empresa alavanque benefícios permanentes, esse processo deve ser contínuo e ter a participação dos colaboradores. A aplicação isolada e momentânea pode garantir ganhos imediatos, porém, não sustentáveis, devido às oscilações do mercado e ao surgimento constante de novas tecnologias.

Os resultados da pesquisa estão embasados nos passos descritos na Figura 1, assim, nas próximas seções serão discutidos como se fez a aplicação, o plano de ação traçado para solucionar os problemas críticos, bem como os resultados obtidos. 


\subsection{Passo 1: treinamento e conscientização dos colaboradores para o pensamento Lean}

Esta etapa iniciou-se gradativamente em conversas informais com o proprietário do Grupo Santa Fé. Elas tiveram como foco demonstrar os benefícios da pesquisa e principalmente os ganhos estruturais e financeiros que a implantação do Lean Office poderia proporcionar a empresa. Em seguida, apresentou-se um projeto com as etapas e os objetivos da pesquisa para que todos os procedimentos ficassem documentados e tivessem assim aceitação.

A maioria dos colaboradores nunca ouvira falar na filosofia Lean, porém, após as explicações e apresentação de resultados obtidos com a aplicação em outras empresas, houve uma maior aceitação de que poderia ser algo que traria benefícios não só à empresa, mas também a si mesmo, no melhor desempenho de suas atividades diárias.

\subsection{Passo 2: MFV - estado atual}

O passo inicial para identificar qualquer desperdício é entender o funcionamento do processo como um todo, assim, o detalhamento das atividades descritas no fluxo torna-se elemento essencial mediante a complexidade de muitos processos. É por meio da análise do mapa das atividades e do valor que elas representam para o cliente, que a equipe de trabalho decide quais melhorias implantar, onde e quando elas devem ser realizadas.

O MFV do estado atual da empresa iniciou com a participação de seis representantes do setor pesquisado. Para ter uma maior participação dos colaboradores, inicialmente as atividades foram descritas em post-it e distribuídas na parede para melhor visualizar o processo. Em seguida, utilizou-se o software BizAgi para modelar as atividades do processo, conforme descrito na figura 2. 


\subsubsection{MFV: estado atual do processo A: recebimento de documentos}

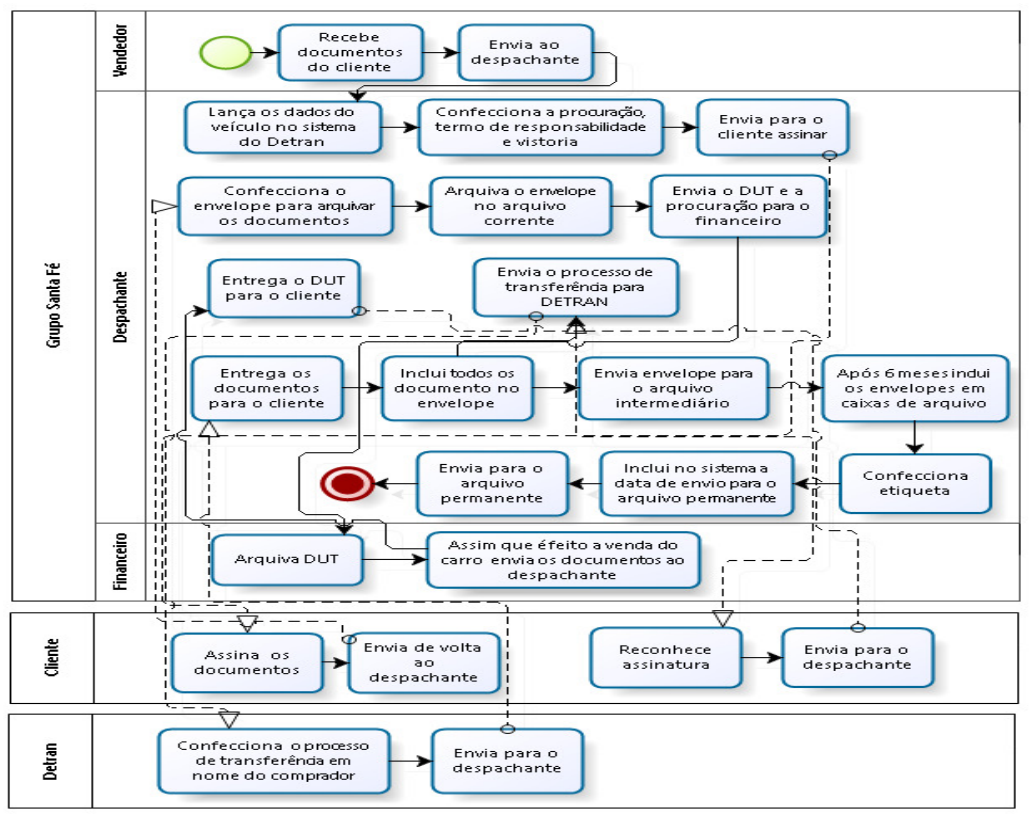

Figura 2 - MFV: estado atual

Fonte: Os autores.

O processo A apresenta 46 atividades, sendo que deste total, apenas 13 apresenta acrescentam valor ao cliente, um percentual de $28 \%$. Com relação ao tempo total de processamento, que é de 241 minutos, as 13 atividades que agregam valor somam um tempo de 87 minutos, representando $36 \%$ do tempo gasto. Dessa forma, destaca-se que $64 \%$ do tempo de processamento é gasto com atividades que não acrescentam valor.

\subsection{MFV: estado futuro do processo A}

A partir da análise do estado atual do processo A, constatou-se que algumas atividades no setor de despachante não agregavam valor, adiando a realização de outras tarefas essenciais, resultando em um processo moroso. Entretanto, algumas atividades desenvolvidas pelo despachante são exigidas pelo órgão que regulamenta o registro dos veículos automotores. Em vista disso, apesar de serem morosas, não foi possível alterá-las devido a burocracia necessária para a conclusão do processo, conforme pode-se visualizar na figura 3 a seguir. 


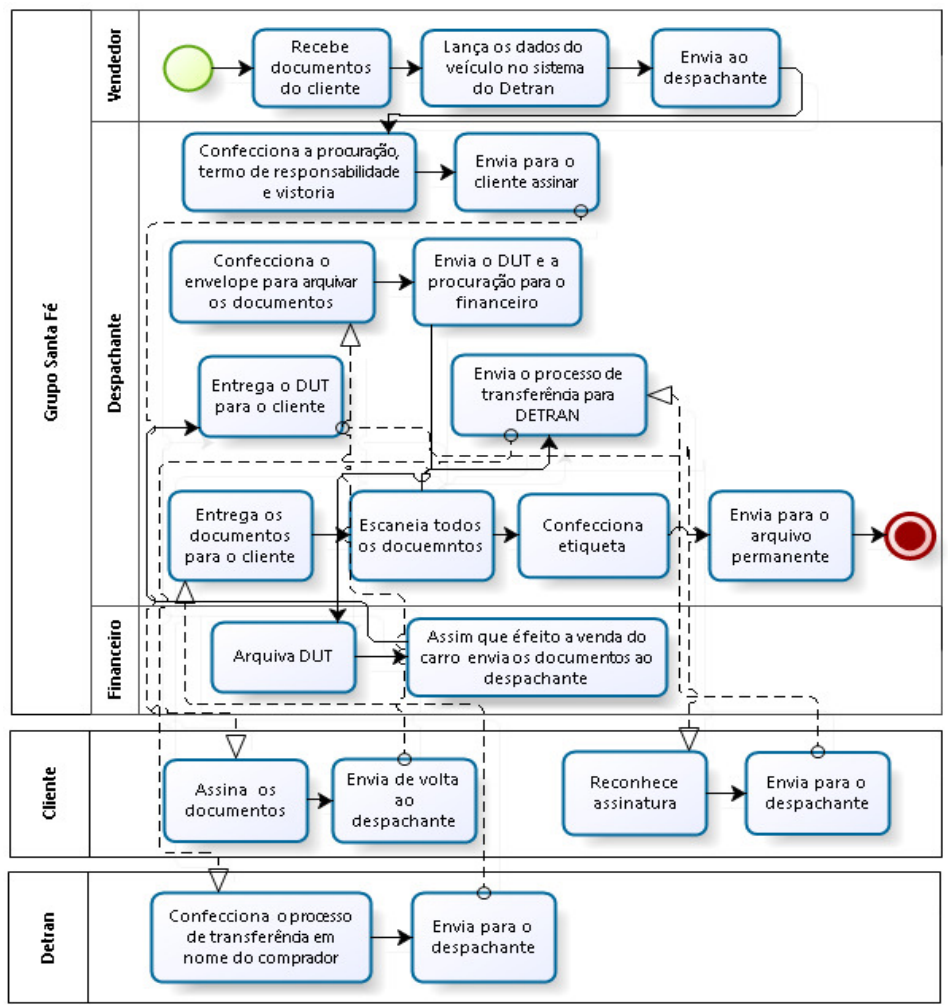

Figura 3 - MFV: estado futuro

Fonte: Os autores.

Após análise e discussão das atividades, foi possível fazer um novo desenho do processo para que fosse mais ágil, menos custoso e que chegasse mais rápido a seu destino final. O MFV do estado futuro foi gerado a partir das expectativas do cliente, pensando na melhor forma de atender às necessidades, mantendo o mais elevado padrão de qualidade, baixo custo de execução e, principalmente, pontualidade e eficiência para suprir as necessidades de recuperação da informação. As mudanças e o resultado das alterações do processo $A$ estão descritos na próxima seção bem como o plano de ação, de modo que a empresa atinja o estado futuro idealizado.

\subsection{PASSO 4: PLANO DE AÇÃO}

Após identificar os desperdícios e o que poderia ser melhorado no fluxo, projetam-se ações, a fim de que cumpra o prazo estabelecido para implementar as melhorias. Para auxiliar a execução do plano de ação, buscou-se auxílio na ferramenta $5 \mathrm{~W} 2 \mathrm{H}$, que é uma ferramenta administrativa simples, fácil de ser implementada e também de grande utilidade aos gestores, pois elimina quase por completo as dúvidas que possam surgir na execução de um processo, aumentando a clareza dos colaboradores acerca das atividades.

Para suprir a necessidade de identificar qual técnica ou ferramenta do Lean Office será aplicada em cada ação, a ferramenta $5 \mathrm{~W} 2 \mathrm{H}$ foi 
adaptada para 5W2H1T. A inclusão do $\mathrm{T}$ representa a letra inicial de técnica ou technique em inglês, utilizada no plano de ação. Cabe salientar que não se pode aplicar integralmente as técnicas e ferramentas Lean, pois elas foram criadas para solucionar problemas da indústria automobilística, porém são passiveis de adaptação.

\subsubsection{Plano de ação do processo A}

No quadro abaixo, estão sistematizadas as ações que foram projetadas e implantadas para o Grupo Santa Fé no processo A.

Quadro 1 - Plano de Ação - 5W2H1T

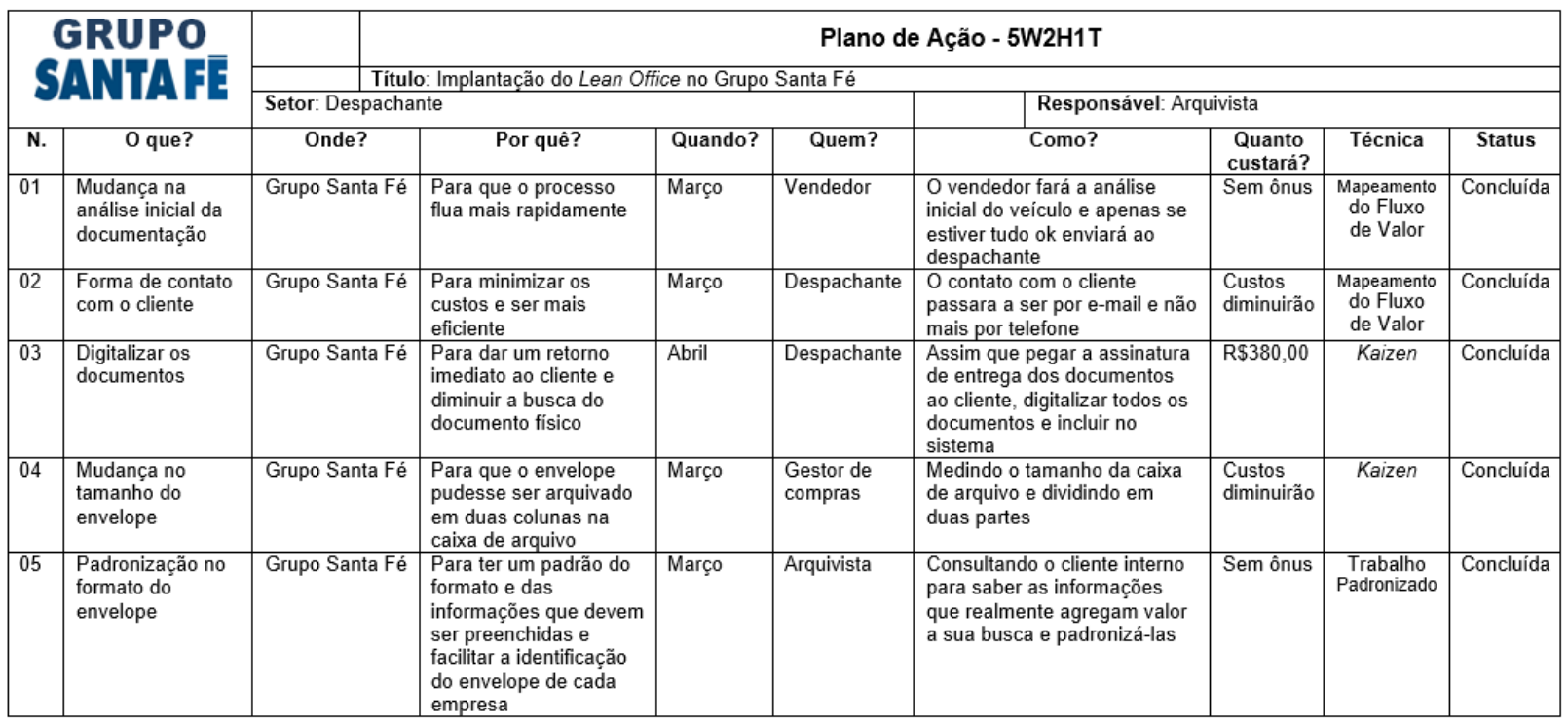

Fonte: Os autores.

Após a sistematização, apresenta-se como se desenvolveram as ações, bem como os resultados desses procedimentos:

$1^{\mathbf{a}}$ ação: Mudança na análise inicial da documentação.

A primeira modificação foi realizada logo no início do processo. Até então a análise da documentação da compra do carro usado era feita apenas pelo despachante no dia seguinte à formalização da compra, culminando em um tempo de retenção de 24 horas. Em caso de restrição, o despachante tinha que enviar novamente a documentação ao vendedor para que ele fizesse o contato com o cliente e só após essa atividade encerraria o processo, isso gerava desperdício de tempo para conseguir contatar o cliente. Com auxílio da ferramenta de Mapeamento do Fluxo de Valor, foi possível eliminar algumas atividades que não geravam valor ao cliente. Em vista disso, a busca inicial passou a ser responsabilidade do próprio vendedor. Assim, caso haja alguma restrição, o processo é encerrado imediatamente, sem ter que passar pelo despachante.

Tendo em vista a ação de mudança na análise inicial da documentação, foi possível diminuir em 1.479 minutos o tempo do 
processo, obtendo uma melhoria de 96,6\%. Este ganho expressivo se deve em grande parte à possibilidade de zerar o tempo de retenção que era de $24 \mathrm{~h}$, porém, se analisar apenas o tempo de processamento, ele também se reduziu em 43,3\%, ficando em 39min, uma vez que se eliminaram algumas atividades que não agregavam valor ao processo.

\begin{tabular}{c|l}
\hline \multicolumn{2}{c}{ Resultado final da $1^{\mathbf{a}}$ Ação - Processo A } \\
\hline Economia de tempo & \multicolumn{1}{c}{ Economia financeira } \\
\hline \hline \multirow{2}{*}{$1479 \mathrm{~min}$} & Colaborador: $39 \min \times 0.273: \mathrm{R} \$ 10,64$ \\
& Telefone: $10 \mathrm{~min} \times 0.69: \mathrm{R} \$ 6,90$ \\
& Total: $\mathrm{R} \$ 17,54$ \\
\hline
\end{tabular}

O cálculo da economia financeira do foi realizado com base no custo de um funcionário em regime da CLT com um salário médio de despachante de $R \$ 2.000,00$, mais $80 \%$ de encargos, tendo um custo mensal de $R \$ 3600,00$. Obteve-se, por fim, que o custo por minuto de um despachante é de $R \$ 0.273$.

O cálculo da economia de telefone fez sobre um custo médio de ligação para celular de $\mathrm{R} \$ 0,69$ por minuto. A projeção média do tempo despendido de ligação para o cliente foi de $15 \mathrm{~min}$, sendo que $5 \mathrm{~min}$ seriam pelas duas tentativas sem custos e os outros $10 \mathrm{~min}$, efetivamente, com 0 contato direto com o cliente.

$2^{\mathbf{a}}$ ação: Forma de contato com o cliente.

Até o momento, o contato com o cliente para entrega dos documentos era feito apenas via telefone, o que muitas vezes se perdia um tempo grande, pois como os contatos são feitos em horário comercial, muitos estavam em horário de trabalho e não atendiam ao telefone. Em decorrência disso, em alguns casos o despachante demorava uma semana para conseguir contato com o cliente em mais de cinco tentativas.

Visando agregar valor e eliminar desperdícios, tanto telefônico, quanto de tempo, optou-se apenas pelo contato via e-mail.

\begin{tabular}{c|l}
\hline \multicolumn{2}{c}{ Resultado final da $2^{\mathbf{a}}$ Ação - Processo A } \\
\hline Economia de tempo & \multicolumn{1}{c}{ Economia financeira } \\
\hline \multirow{3}{*}{$13 \min$} & Colaborador: $13 \min \times 0.273: \mathrm{R} \$ 3,55$ \\
& Telefone: $10 \min \times 0.69: \mathrm{R} \$ 6,90$ \\
& Total: $\mathrm{R} \$ 10,45$ \\
\hline
\end{tabular}

$3^{\mathbf{a}}$ ação: Digitalizar os documentos.

A essência do Kaizen preconiza a mudança para melhor, ou melhoria contínua. Com esse intuito, optou-se por incluir uma atividade no processo para melhorá-lo e ter a possibilidade de eliminar outras duas, que é a de digitalizar todos os documentos relacionados à transição do veículo na concessionária assim que for finalizado a venda e a entrega dos documentos ao novo proprietário. 
Tendo em vista a nova atividade, elimina-se o arquivo intermediário, pois só era mantido devido as constantes buscas ao documento físico.

\begin{tabular}{c|c|c}
\hline \multicolumn{3}{c}{ Resultado final da 3 $3^{\mathbf{a}}$ Ação - Processo A } \\
\hline Economia de tempo & \multicolumn{1}{|c}{ Economia financeira } & Economia de espaço físico \\
\hline \hline $7 \mathrm{~min}$ & $\begin{array}{c}\text { Colaborador: } 7 \min \times 0.273: \mathrm{R} \$ 1,91 \\
\text { Total: } \mathrm{R} \$ 1,91\end{array}$ & $6 \mathrm{~m}^{2}$ \\
\hline
\end{tabular}

4a Ação: Mudança no tamanho do envelope.

Os envelopes de despachante usados para guardar toda documentação da transição de um veículo na concessionária apresentavam um tamanho de $28 \mathrm{~cm}$ comprimento por $20 \mathrm{~cm}$ de largura. Entretanto, identificou-se que os documentos geralmente são pequenos e os maiores apresentam o tamanho A4 $(21 \mathrm{~cm} \times 27,7 \mathrm{~cm})$, logo o envelope poderia ser menor. Analisando o tamanho da caixa de arquivo $(35 \mathrm{~cm} \times$ $24,5 \mathrm{~cm}$ ) optou-se por diminuir o tamanho do envelope para $24 \mathrm{~cm}$ de comprimento por $17,5 \mathrm{~cm}$ de largura, assim, a guarda dos envelopes pode ser feita em duas colunas.

Essa nova organização possibilitou uma redução de custos com material de escritório e espaço físico de $50 \%$, pois o número de caixas de arquivo e etiquetas que antes era de 180 ano passou a ser de 90 ano.

\begin{tabular}{|c|c|c|}
\hline \multicolumn{3}{|c|}{ Resultado final da $4^{\mathrm{a}}$ Ação - Processo A } \\
\hline Economia de tempo & Economia financeira & Economia de espaço físico \\
\hline--- & $\begin{array}{ll}\text { Caixa de arquivo: } 90 \times 3,5: & \mathrm{R} \$ 315,00 \\
\text { Etiquetas: } 90 \times 0,075: & \mathrm{R} \$ 6,75 \\
\text { Tinta de impressora: } 90 \times 0,2: \mathrm{R} \$ 18,00 \\
\text { Aluguel: } 2,5 \times(8,5 \times 60): & \mathrm{R} \$ 1.275,00 \\
\text { Estantes: } 2,5 \times 160,00: & \mathrm{R} \$ 400,00 \\
\text { Total: } & \mathrm{R} \$ 2.014,75\end{array}$ & $12,5 \mathrm{~m}^{2}$ \\
\hline
\end{tabular}

Os custos com material de escritório e do aluguel foram calculados sobre os valores atuais de mercado.

5a Ação: Padronização no formato do envelope.

$\mathrm{Na}$ empresa existiam três modelos incompatíveis de envelope que dificultavam a identificação imediata da tipologia, com isso, além do tamanho do envelope, optou-se por padronizar as informações e a estrutura da capa.

Os novos modelos, além de padronizados, apresentam menos informações para o preenchimento. O modelo antigo continha 31 campos de preenchimentos, a grande maioria desnecessários, pois nunca eram consultados. Identificando o fluxo de valor do cliente para avaliar as informações que realmente são necessárias à sua consulta, o novo modelo apresenta apenas 11 campos de preenchimento, com isso, a atividade que era realizada em 12 minutos, passou a ser feita em menos de 4 minutos, possibilitando que o processo flua mais rápido. 


\begin{tabular}{c|l}
\hline \multicolumn{2}{c}{ Resultado final da $5^{\mathbf{a}}$ Ação - Processo A } \\
\hline Economia de tempo & \multicolumn{1}{|c}{ Economia financeira } \\
\hline \hline \multirow{3}{*}{$8 \mathrm{~min}$} & Colaborador: $8 \min \times 0.273: \mathrm{R} \$ 2,18$ \\
& Papel: $1800 \times 0.04: \mathrm{R} \$ 72,00$ \\
& Total: $\mathrm{R} \$ 74,18$ \\
\hline
\end{tabular}

Na seção seguinte, descreve-se o último passo da implantação do Lean Office no Grupo Santa Fé, contendo a avaliação de como se desenvolveu a aplicação, com as dificuldades e desafios encontrados e uma discussão dos resultados alcançados.

\subsection{Passo 5: avaliação e discussão dos resultados}

Após o alcance do estado futuro, os resultados consolidados foram expressivos e reduziram o tempo do ciclo dos processos, com isso gerou uma economia financeira para empresa e aumentou o espaço livre para guarda de novos documentos.

Muitas técnicas e ferramentas do Lean Office foram adaptadas à realidade do estudo, porém, sua essência se manteve e os benefícios que foram identificados em outros segmentos também puderam ser usufruídos agora na gestão de arquivo.

Com o fim da implantação dos conceitos do Lean Office na gestão de arquivos, pode-se listar alguns princípios que foram seguidos e adaptados à realidade estudada. Tais princípios podem ser úteis para direcionar outros trabalhos no mesmo segmento e ajudar sua aplicação, tendo em vista a dificuldade de encontrar na literatura trabalhos que proporcionassem um melhor entendimento sobre o assunto.

Foram estabelecidos dez princípios que podem ser utilizados para transformar arquivos tradicionais, pouco eficientes, em arquivos enxutos, priorizando sua máxima eficiência com a eliminação de desperdícios vivenciados nesses ambientes. Os princípios e suas descrições são apresentados a seguir:

a) monitorar e controlar os processos do arquivo: ter conhecimento de todas as atividades que envolvem o processo e saber os níveis de eficiência de seu funcionamento;

b) reconhecer o valor dos documentos do ponto de vista do cliente: saber quais documentos são mais importantes para o cliente, que possuem um valor legal diferenciado e que precisam de um tratamento prioritário. Os que já não possuem mais valor para o cliente devem ser descartados;

c) identificar o desperdício de materiais e recursos: usar apenas os recursos e material de escritório essenciais para o desenvolvimento das atividades; 
d) eliminar as atividades que não agregam valor: identificar quais atividades agregam valor ao cliente $e$, as que não apresentam, eliminá-las;

e) simplificação do número de passos para arquivamento: minimizar a tramitação dos documentos em vários setores para que ele não se perca e possa ser arquivado com segurança;

f) reduzir espaço de arquivamento entre os documentos: as caixas de arquivo devem ser preenchidas em sua totalidade, para que não haja desperdício material e espaço físico do arquivo;

g) diminuir o tempo de recuperação do documento: criar técnicas de arquivamento voltadas para uma recuperação mais eficiente;

h) aumentar a efetividade nas buscas: conferir e monitorar todo documento que entra no arquivo para que sua recuperação seja possível;

i) ampliar o retorno dos documentos emprestados: controlar de forma efetiva o empréstimo dos documentos para que se tenha o total retorno;

j) busca pela melhoria contínua dos processos: almejar a perfeição em todas as atividades desenvolvidas.

\section{Conclusão}

A pesquisa cumpre o objetivo principal de aplicar o Lean Office na gestão de arquivo, tendo em vista o alcance de todos os objetivos específicos da pesquisa. O MFV do estado atual foi possível devido à participação efetiva dos pesquisados no grupo focal. Assim, ocorreu a descrição do fluxo das atividades dos processos em post-it e se quantificou o tempo gasto em cada atividade, para melhor estruturar em que local se poderia agilizar ou excluir determinada tarefa que possuía alto tempo de processamento ou retenção e não agregaria valor ao cliente.

Com as atividades descritas e colocadas de forma sequencial na parede para uma melhor visualização do fluxo, foi possível identificar oportunidades de melhorias, destacando atividades que poderiam ser melhoradas, implantadas ou eliminadas, pois com aquisição de novos equipamentos e melhora de determinadas atividades eliminaram-se algumas que atrasavam o processo e tornavam-no mais moroso.

Identificadas as prováveis melhorias, traçou-se MFV do estado futuro e assim um plano de ação para que elas fossem executadas. Para que o plano de ação pudesse ser acompanhado, o grupo focal decidiu 
designar os responsáveis pela implantação de cada ação, assim como o prazo estabelecido para implementá-las. A divisão das tarefas foi feita para que todos participassem e assim houvesse mais comprometimento da equipe.

Durante o plano de ação, identificaram-se quais técnicas e ferramentas do Lean Office poderiam ser utilizadas para promover as melhorias nos processos mapeados. Essas técnicas tiveram que ser adaptadas para a realidade da gestão de arquivo, tendo em vista que se utilizaram originalmente na manufatura, em outra realidade.

Entre os principais resultados pode-se citar uma redução do tempo médio para a realização dos processos, com ganhos expressivos, tanto nas atividades de processamento, quanto nas de retenção. A redução desse tempo e de outros desperdícios eliminados, que não geravam valor ao cliente, gerou ganhos financeiros em diversas atividades, que podem ser repassados ao setor para melhor se estruturar e auxiliar ainda mais o Grupo no cumprimento da sua missão.

Tendo em vista as análises realizadas, pode-se concluir que o uso do método para executar melhorias na gestão de arquivos gerou resultados acima do esperado. Uma das hipóteses da obtenção desses resultados representativos, está relacionada ao fato de que poucos estudos atualmente são direcionados para melhorar a prática da gestão de arquivos. Poucas empresas demonstram interesse em melhorar setores que são atividades-meio na maioria das instituições. Neste sentido, a gestão da informação ainda tem muito a evoluir e novas pesquisas podem proporcionar ganhos ainda maiores, contribuindo não só para melhorar a gestão nesses setores, mas também na empresa como um todo, já que é um local que tem relação com todos os setores da empresa.

\section{Referências}

BRASIL. Presidência da República. Lei n. 8.159, de 8 de janeiro de 1991. Dispõe sobre a política nacional de arquivos públicos e privados. Diário Oficial da União, Brasília, DF, 9 de jan. 1991. Disponível em: <http://www.planalto.gov.br/ccivil_03/leis/L8159.htm>. Acesso em: 8 fev. 2016.

CAVAGLIERI, M.; LOPES, U. dos S.; ROSÁRIO, O. do. Gestão de arquivos e a importância de um profissional da informação: análise do cartório do 20 ofício de registro de imóveis. Revista ACB: Biblioteconomia em Santa Catarina, Florianópolis, v. 14, n. 1, p. 216-237, jan./jun. 2009.

CAVALCANTE, L. de F. B.; VALENTIM, M. L. P. Informação e conhecimento no contexto de ambientes organizacionais. In: VALENTIM, M. L. P. (Org.). Gestão, mediação e uso da informação. São Paulo: Cultura Acadêmica, 2010. p. 235-254.

DUDZIAK, El. A. Arquivos e documentos empresariais: da organização cotidiana à gestão eficiente. Revista de Gestão e Secretariado, São Paulo, v. 1 , n. 1 , p. 90-110, jan./jun. 2010. 
GREEF, A. C.; FREITAS, M. do C. D.; ROMANEL, F. B. Lean Office: operação, gerenciamento e tecnologias. São Paulo: Atlas, 2012.

MARCHIORI, P. Z. A ciência e a gestão da informação: compatibilidades no espaço profissional. Ciência da Informação, Brasília, v. 31, n. 2, p. 7279, 2002.

MORGAN, D. L. Focus group as qualitative research. London: Sage, 1997.

OHNO, T. O Sistema Toyota de Produção: além da Produção em Larga Escala. Porto Alegre: Bookman, 2006.

PINTO, M. M. G. de A. O novo paradigma da arquivística: um estudo de caso. $2001 . \quad$ Disponível em: <http://ler.letras.up.pt/uploads/ficheiros/3090.pdf>. Acesso em: $10 \mathrm{fev}$. 2016.

SCALERA, F. International crisis and competitiveness of service companies and public administration in Italy and in Europe: the application of lean office. Business and Management Review, v. 2, n. 1, p. 63-75, 2012.

TAPPING, D.; SHUKER, T. Lean Office: gerenciamento do fluxo de valor para áreas administrativas; 8 passos para planejar, mapear e sustentar melhorias Lean nas áreas administrativas. São Paulo: Leopardo, 2010.

THIOLLENT, M. Pesquisa-ação nas organizações. São Paulo: Atlas, 1997.

WOMACK, J. P.; JONES, D. T. A mentalidade enxuta nas empresas: elimine o desperdício e crie riqueza. 9. ed. Rio de Janeiro: Elsevier, 2003. 